\title{
Optimized battery sizing for merchant solar PV capacity firming in different electricity markets
}

\author{
J. Cardo-Miota, H. Beltran, P. Ayuso, J. Segarra-Tamarit, and E. Perez \\ Department of Industrial Systems Engineering and Design \\ Universitat Jaume I \\ Castelló de la Plana, Spain \\ e-mail: hbeltran@uji.es // ORCID: 0000-0002-7223-0214
}

\begin{abstract}
This work analyses the minimum energy capacity requirements to be demanded to battery energy storage systems used in megawatt-range merchant solar PV plants to grant capacity firming. The operation of such a plant is simulated (with a 2-minute time step, at three different locations of the Iberian Peninsula, and for different battery sizes) after solving a quadratic programming optimization problem. The control algorithm takes into account the irradiance forecast and the intraday electricity market configuration, which presents certain peculiarities in the Iberian region with regard to other European markets. The analysis has been performed in an annual basis and current irradiance measured values have been used.
\end{abstract}

Keywords-merchant solar PV, electricity markets, power generation planning, energy storage systems.

\section{INTRODUCTION}

The strong potential of renewable energies as a clean source of electricity presents no further discussion worldwide as its massive deployment spreads all around. Among the different technologies available to produce electricity, the photovoltaic (PV) energy is leading the market nowadays. After experiencing a continuous growth for more than 10 years, PV overtook wind technology in 2016 leading the annually added installed capacity around the world. In this way, it finished 2017 incorporating more than 90 GW 2017 [1]. Estimates for 2018 are around other $95 \mathrm{GW}$ to reach a global installed PV capacity above $480 \mathrm{GW}$ [1]. This evolution is being achieved thanks to the economies of scale that made PV the most competitive technology in terms of $€ / \mathrm{kWh}$ produced [2]. Among all these GWs, many of them belong to huge projects in the range of hundreds of MWs that are being installed in most of the continents. Such big plants may start introducing challenges to the operation of regional grids because their production is not dispatchable [3]. It should be remembered that PV is a technology whose production is inherently intermittent, dependent on the cloud movement patterns through the day. This prevents PV plants from granting a predictable production at any given moment.

Concurrently, the decrease in the prices of several energy storage (ES) technologies during the last 5 years, mainly for Li-ion batteries, and the expected future trends [4] opened the door to their use in parallel with PV plants. It has already been proposed in the literature the possibility to use the ES system (ESS) as an energy buffer that could enhance the controllability of the plant's production in different ways: power smoothening [5], ramp rate control [6], voltage control [7], among others... Nowadays, hybrid PV+ES plants, Fig. 1, have become a reality and are used not only for those applications but also as a commercial contender to substitute peaker thermal plants [8]. Therefore, battery ESS (BESS) enhance the operability of PV plants and can help providing this historically intermittent technology with capacity firming, i.e. dispatchability. However, batteries are still an expensive element that increases the cost of the installation considerably, reducing the profitability of the overall investment. Therefore, their sizing has to be optimized in order to reduce the extra CAPEX of the plant.

This work analyses and discusses the minimum energy capacity requirements that should be demanded to a BESS to be introduced in a $10 \mathrm{MW}$ merchant solar PV plant to grant capacity firming. The analysis is performed in an annual basis at three different locations of the Iberian Peninsula. These present different irradiance patterns to generalize results. The operation of the plant is simulated (with a 2minute time step and various BESS sizes) after solving a quadratic programming optimization problem. This takes into account the irradiance forecast and the intraday Iberian Electricity Market (MIBEL) configuration, which presents certain peculiarities with regard to other European markets.

The paper starts by describing the MIBEL intraday market, and an alternative proposed. Then, the algorithm proposed to control the PV + BESS plant with optimized capacity firming while keeping the battery requirements to the minimum is introduced. Together with that, Section III describes the methodology used to generate solar irradiance models for the control algorithm. Section IV is devoted to the definition of the BESS energy capacity requirements to operate the PV power plant with the proposed control algorithm under the two intraday market structures. Finally, some concluding remarks are presented in Section V.

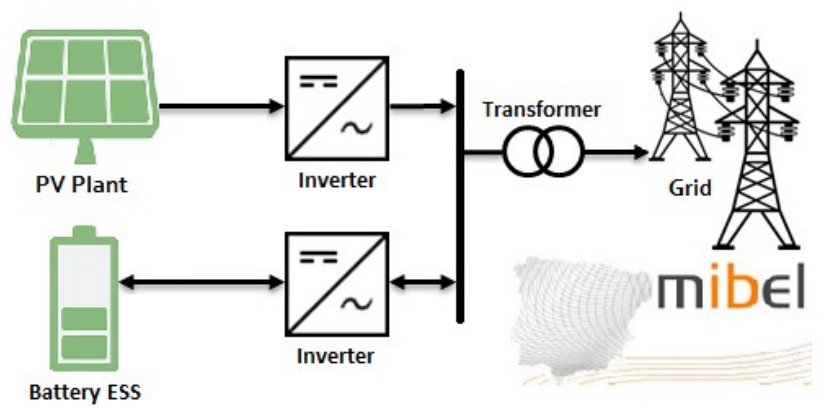

Fig. 1. Solar merchant PV plant with BESS connected to MIBEL. 


\section{INTRADAY ELECTRICITY MARKETS}

Most of the competitive electricity markets around the world present similar structures nowadays, with both forward and real-time options to negotiate the exchange of electricity. In all, markets can be split into those presenting a pool-based spot model, those based on bilateral contracts and those that present both options, i.e. hybrid models [9]. Note that while in the pool spot market electricity is traded centrally on a power exchange that clears the market for the buyers and sellers normally once a day, in the bilateral contract systems electricity is traded directly peer-to-peer between market participants. Both types of markets experience challenging situations when unexpected generator outages or unexpected changes in demand arise. These casuistic can take place anytime in between the closure of the day-ahead market, or the moment when the bilateral contract is settled, and the time when the energy has to be delivered. Therefore, some mechanisms are introduced to correct such contingencies. These mechanisms take the form of intra-daily auctions within the so-called intraday markets. The different sessions opened throughout the day at which the intraday market is active allow traders to renegotiate their electricity production/consumption compromises in case of need (or commercial opportunity). In this sense, intraday markets have historically been in Europe more or less continuous trading markets that opened from 6 to 24 times per day, depending on the country, with a gate closure set one to three hours ahead of the settlement period [10].

For the case of the MIBEL [11], the Spanish-Portuguese market taken as a framework for the analysis introduced in this work, its intraday market has traditionally been divided into six sessions (with different programming horizons) regularly distributed throughout the day (every four hours) with operational settlement periods (OSP) of one hour, upper Fig. 2. Note how this market presents an auction closing time $2 \mathrm{~h}: 15 \mathrm{~min}$ before the start of the OSP, a still quite-long period that can be critical for the goodness of the production forecast. However, as it only presents six sessions, this is a very liquid configuration.
In 2015, the European Commission dictated its Regulation 1222, of July 24, that established a guideline on capacity allocation and congestion management in Europe and defined an objective model for intraday markets based on the continuous negotiation of energy. The goal of the Regulation was to achieve an integrated intraday European market with 24 sessions. With this "continuous" intraday market, the possibility that market agents can manage their energy imbalances and rely on their production forecasts is significantly improved. Moreover, in order to avoid the lack of liquidity at the national/regional level, they can also benefit from the liquidity available in the markets of other bidding zones provided that there is capacity available to cross-border transport between the zones.

The Iberian Peninsula keeps being quite isolated in this sense and still presents a poor degree of interconnection with France (lower than the $10 \%$ promoted by ENTSO-E). This implied some concerns at the MIBEL grid operator level and derived different proposals of integration. Among them, a very interesting option was to temporarily transform the MIBEL intraday market into that in the lower part of Fig. 2. It should present 8 sessions, instead of 6 , with an auction closing time just $1 \mathrm{~h}$ and $10 \mathrm{~min}$ before the start of the OSP. This intermediate proposal also improved the reliability of the production forecast, shortening the time in between bid and energy delivery, while keeping a good liquidity at the national market level (avoiding potential restrictions associated to the lack of interconnections). Due to the potential benefits that this intraday market structure would imply for the introduction of BESS in PV power plants, the two configurations represented in Fig. 2 have been analysed in this work. Thus, the production of the PV plant with BESS has been optimized, as described in Section III, to be traded with guaranties (that is, with the minimum battery size that would avoid deviations) in both scenarios.

Finally, note that the final intraday market configuration implemented in Europe from June 2018 onwards makes it compatible to keep certain regional intraday auctions with the whole continuous (24 sessions) pan-European model.

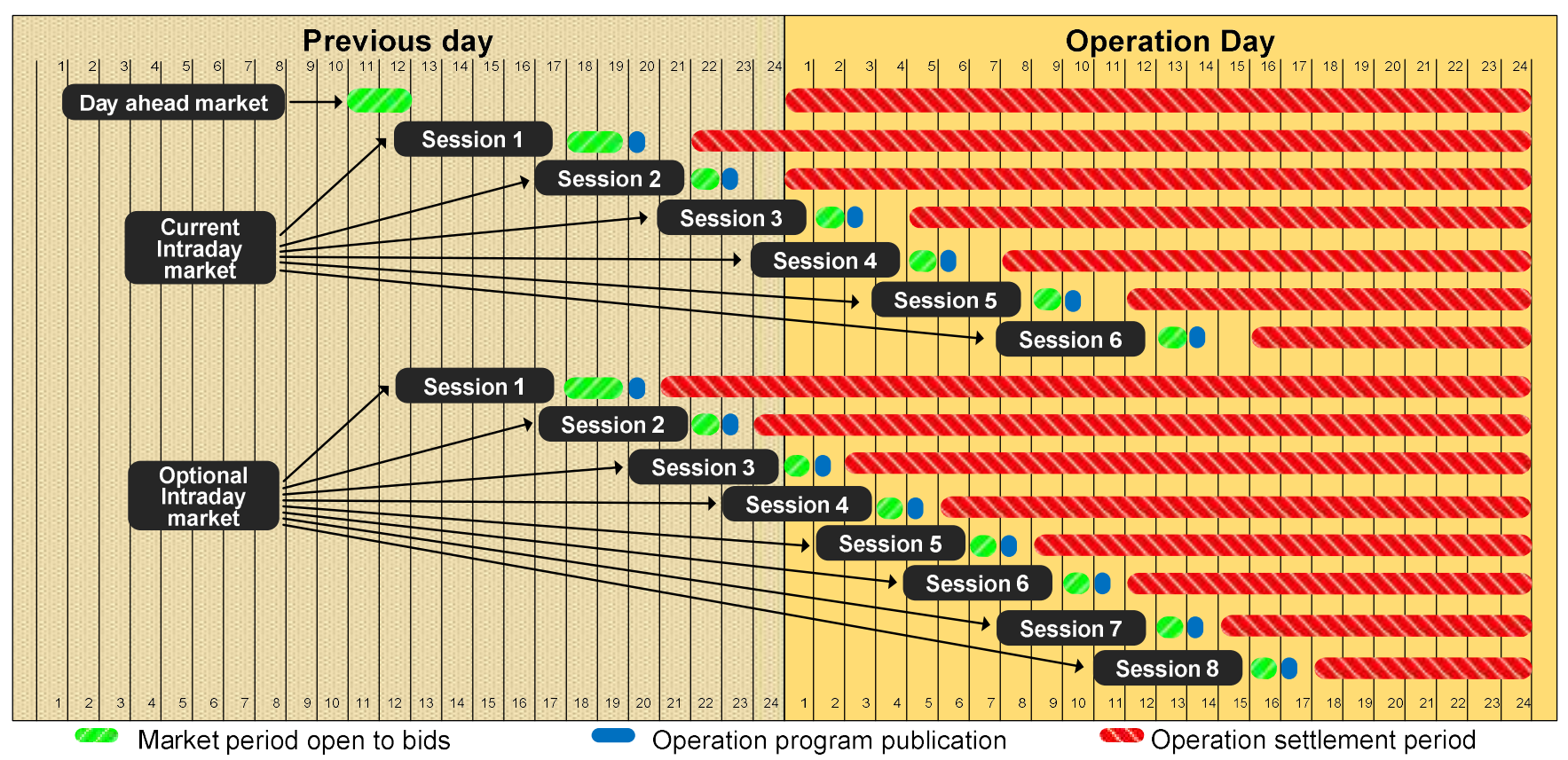

Fig. 2. Timing of the daily and the intrady markets (official, and analysed proposal) for the Iberian Electricity Market (MIBEL). 


\section{PV WITH BESS CONTROL}

\section{A. Optimization problem}

The control algorithm used in this work intends to profit the improved performance capabilities associated to largescale merchant PV plants hybridized with BESS while minimizing the energy capacity requirements of the BESS. It is well known that with such a hybrid configuration the PV production becomes independent from the current real-time local weather conditions, turning the power plant production dispatchable, thanks to the complementary energy available in the BESS. This fosters the participation of the plant in the electricity markets. Thus, since the idea is analysing minimum battery energy capacity that provides a reliable capacity firming operation of the hybrid plant taking profit of the intraday market sessions, the control algorithm implemented to calculate the BESS power exchange is executed periodically throughout the day. This control algorithm, based on the proposal in [12], can be formulated as follows:

$$
P_{E S}(t)=\left(P_{r e f}^{*}(t)-P_{p v}(t)\right)
$$

with $P^{*}{ }_{r e f}$ being the power committed to the market, $P_{p v}$ the real-time power provided by the PV panels, and $P_{E S}$ the power to be exchanged by the ES to complement PV production. This is, in turns,

$$
\begin{array}{ll}
\text { Discharge: } & P_{E S}>0 \rightarrow d E_{E S}(t) / d t=-P_{E S} / \varepsilon_{d} \\
\text { Charge: } & P_{E S}<0 \rightarrow d E_{E S}(t) / d t=-P_{E S} \cdot \varepsilon_{c}
\end{array}
$$

where $E_{E S}$ is the available energy in the ESS, $\varepsilon_{c}$ the charging efficiency, and $\mathcal{E}_{d}$ the discharging efficiency. The $E_{E S}$ is permanently accounted for by controlling the state-ofcharge (SOC) of the ESS.

$P^{*}{ }_{r e f}$ is a key operation parameter for a merchant solar PV plant and represent the hourly-averaged power values committed in the market that are to be maintained with minimum deviations, to avoid penalties derived from them. These committed production values are usually defined according to the energy management strategy (EMS) of the plant. Various EMS implemented to drive PV plants with BESS can be found in the literature [13]-[17]. The present work uses an EMS called "hourly constant-power steps" in [12]. According to this, to define the power value for each of the 24 hourly operation periods within a day, the EMS performs an optimization of the $P^{*}{ }_{\text {ref }}$ using quadratic programming (QP). This methodology solves the problem of optimizing a quadratic function with several variables subject to linear constraints. The target for the mathematical optimization performed is to permanently keep the battery SOC as close as possible to a reference value, in order to require the shortest energy capacity. This optimization is defined by

$$
\min \sum_{0}^{n}\left(S O C_{i}-S O C_{r e f}\right)^{2}
$$

with $S O C_{i}$ being the BESS charge level at any sample in the day under operation, and $S O C_{r e f}$ its reference value, which is typically $50 \%$ of the BESS capacity. This QP optimization is subject to the following linear constraints:

$$
\begin{aligned}
& P_{r e f}(t)= \begin{cases}p_{1} & t=0 \ldots . .30 \\
p_{2} & t=31 \ldots . .60 \\
\ldots . & \\
p_{24} & t=691 \ldots . .720\end{cases} \\
& P_{r e f}(t)=P_{p v}(t)+P_{E S}(t) \quad t=0, \ldots, 720 \\
& P_{\text {min }}<P_{E S}(t)<P_{\max } \quad t=0, \ldots, 720 \\
& E_{E S}(t)=E_{E S}(t-1)-T \cdot P_{E S} \quad t=0, \ldots, 720 \\
& E_{\min }<E_{E S}(t)<E_{\max } \quad t=0, \ldots, 720
\end{aligned}
$$

It can be noted how the total number of samples considered in the optimization is 720 , corresponding to the number of 2-min periods (sampling period for the analysis performed in the present paper) in one day. Thereby, check in (5) how each of the 24 power values defined with this optimization lasts 30 samples (one hour). Four additional restrictions have been introduced. Those in (6) and (7) lay down the functioning of the hybrid power plant, as already introduced by (1), and also some power limitations in the BESS power setpoint (derived from the BESS connection power converter ratings), respectively. Moreover, (8) and (9) define restrictions over the evolution of the battery SOC throughout the daytime and, also, what the SOC maximum and minimum levels are. Finally, note that charging or discharging efficiency coefficients, which would be of use in (8), have not been introduced into the model. This is so because their presence would imply a nonlinear behaviour of the system and this would require a different optimization methodology to be solved. Nonetheless, given their importance in the real operation of the system, the energy losses associated to these inefficiencies represented in (2) and (3) have been indeed included in the annually-based simulation performed to determine BESS ratings.

It is important to highlight at this point that the QP calculation is launched for the first time the day before the day-on-schedule. The resulting power values, $P_{\text {ref }}$ Initial, correspond to the 24-hour production program that the PV plant operator commits in the daily electricity market. It results essential in this extent to use a precise daily solar irradiance model to obtain an accurate production program. The irradiance evolution reference model used in this case with that goal is explained in the following subsection. However, since the exact daily irradiance evolution and the corresponding instantaneous $P_{p v}$ cannot be known in advance, PV production deviations with regard to the commitment are encountered. This implies a permanent use of the BESS to provide capacity firming and avoid economic penalties, as well as the corresponding battery SOC fluctuations.

Since electricity markets worldwide offer opportunities for generators to adjust their power commitments along the day, some refinements can be introduced during the daytime using the various available intraday market sessions. Therefore, the QP calculation is launched again at every intraday session just before the closing of the bids period. This renewed calculation uses updated information on the actual $S O C_{i}$ and provides successive $P_{r e f}$ that progressively modify the power commitment of the plant for the still lasting hours of the day-on-schedule. The final commitment after the various recalculations is defined as "Final ref". 


\section{B. PV Clustering}

In order to perform the optimization just introduced, our control algorithm requires the continuous introduction of a PV production forecast or reference model. This provides the control system guidance on the potential evolution of $P_{p v}$ and allows defining the optimal $P_{\text {ref }}$ to be committed in the market to minimize the saturation of the ES, thus minimizing its size. In order to generate this PV production reference, the well-known k-Means clustering algorithm (already existing and implemented in Matlab $^{\circledR}$ ) has been used [18]. This function partitions data into $\mathrm{k}$ distinct clusters based on the squared Euclidean distance of the data classified to the centroid of a cluster. The past registered irradiance at the various locations analysed was, in this case, the data fed to the k-Means clustering algorithm. This provided a total of 5 clusters for each location that bundle the 365 annual daily solar irradiance profiles according to their evolution characteristics. In this way, every day is associated to a given cluster which can be represented by its centroid evolution. This evolution was used as the PV production reference required. It is important to notice that, for those locations whose past registered irradiance data covered more than one year, the clustering results were very similar among years, Fig. 3. This confirms the validity of the clusters as reference patterns for the different type of days, in terms of irradiance, that can be potentially experienced at a given location.

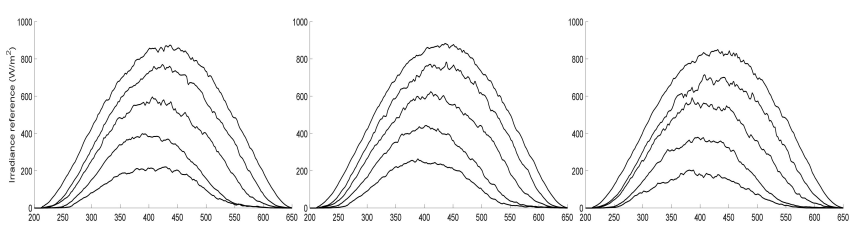

Fig. 3. Solar irrandiance clusters for three different years in alocation.

Note also that, for some of the locations, k-Means was capable of identifying interesting daily solar irradiance evolutions such as those in days mostly clear in the morning and cloudy in the afternoons, Fig. 4, or vice versa, Fig. 5.

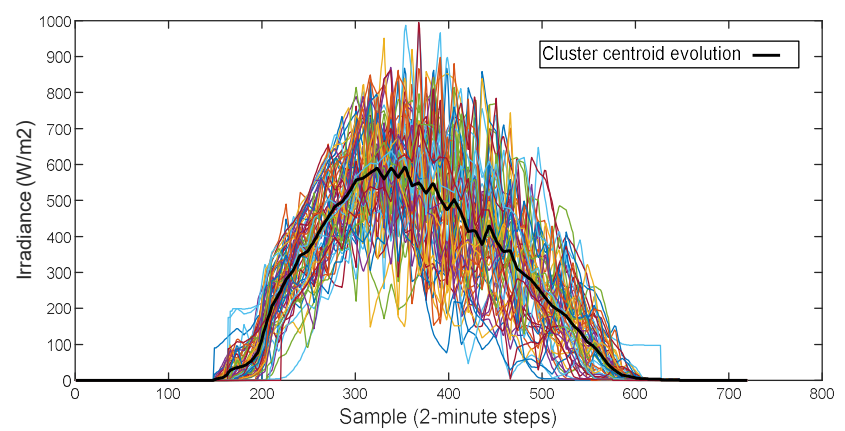

Fig. 4. Example of cluster bundling days presenting a mostly clear morning and a cloudy afternoon at a given location.

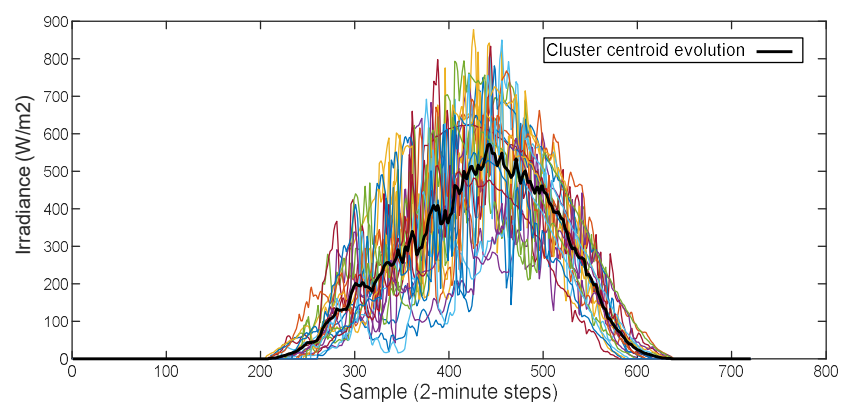

Fig. 5. Example of cluster bundling days presenting a cloudy morning and a mostly clear afternoon at a given location.
Therefore, k-Means returned the evolutions of the cluster centroid together with the list of days incorporated to each of the clusters. Both datasets were used in the optimization.

\section{Results of the optimization}

Using the aforementioned methodology, annual optimizations of the PV + BESS power plant operation were performed. The simulation was run day after day providing system operations as those introduced as example for a clear and a cloudy day in Fig. 6 and Fig. 7, respectively. Note how the control algorithm generates the corresponding and successive $P_{\text {ref }}$ (both the initially defined for the day-ahead market (continuous red line) and the final one, "Final ref", obtained from the successive refinements of the operation performed during the intraday sessions (dotted magenta and green lines). These are used as commitment and are tracked by the power plant. Check in these figures how, regardless of the similarity between the actual irradiance (continuous yellow line) and the used cluster's reference centroid (no matter if the day is clear and closer to its reference centroid or cloudy and very different), the "Final ref" progressively differs from the Initial $P_{r e f}$ as time goes by throughout the day. This is due to the control algorithm trying to compensate the production deviation from that modelled and to recover the SOC to its reference to the soonest in the coming samples.

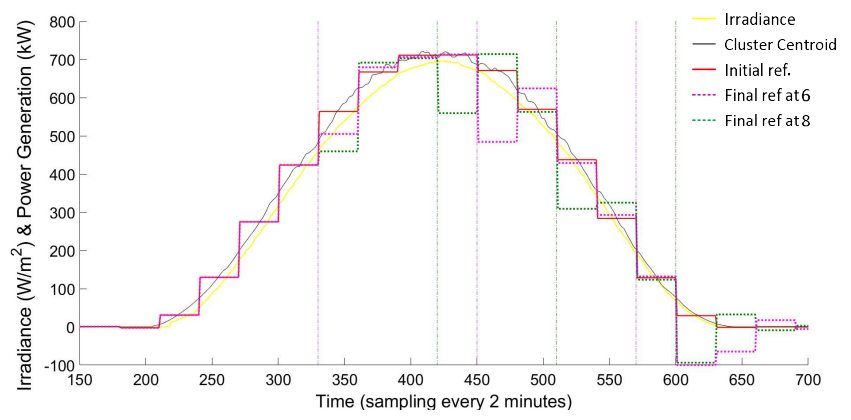

Fig. 6. Example of $P_{\text {ref }}$ obtained for a completely clear day in both an intraday market structure with 6 and 8 sessions.
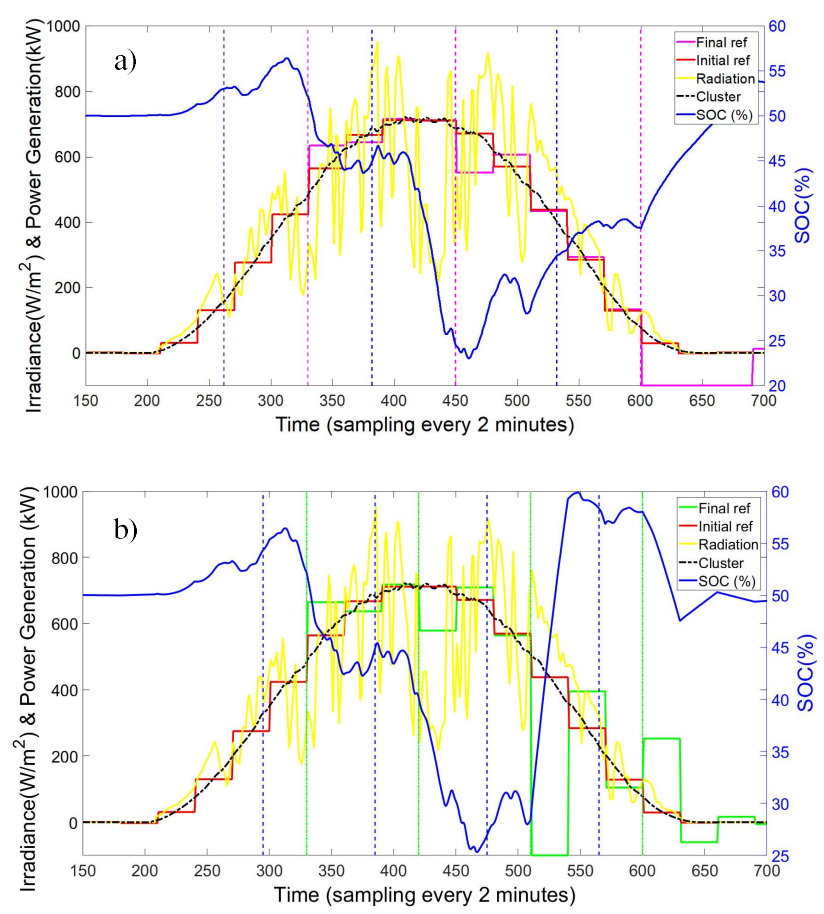

Fig. 7. Example of plant operation (with SOC) obtained for a) a cloudy day and an intraday market structure with 6 sessions, and b) the same cloudy day and an intraday market structure with 8 sessions. 
Besides, note how the time at which the different OSP start for each of the two market configurations has been pointed out with the vertical magenta and green dashed lines introduced three and four times, respectively, in Fig. 7 a) and b). The moments at which the bids are closed are pointed out with blue dashed lines for both market structures $(2 \mathrm{~h}: 15 \mathrm{~min}$ and $1 \mathrm{~h}: 10 \mathrm{~min}$ prior to OSP, respectively).

Therefore, check how the operation of the plant responds to the control algorithm explained, varying the future $P_{\text {ref }}$ every time an OSP is achieved. This variation is mainly influenced, to differ it from the previous reference, by the actual SOC of the BESS at the moment of the bids closure. Then, it is to be highlighted when observing Fig. 7 a) and b) how the successively refined "Final ref" curves differs as a function of the number of sessions that the intraday market presents. The higher the number of sessions, the more frequently the $P_{\text {ref }}$ is recalculated to produce a more refined "Final ref", and also the shorter the time in between bids closure and OSP.

Finally, also note how the evolution of the battery SOC (continuous blue lines) consequently differs as a function of the different intraday market configuration analyzed, in accordance with that stated in the previous paragraph. In fact, it is important to notice the changes experienced in the SOC between Fig. 7 a) and b). These results, that have been obtained while considering a $10 \mathrm{MW}$ merchant solar PV plant with a rated $10 \mathrm{MW} / 20 \mathrm{MWh}$ BESS, anticipate that the intraday market structure with 8 intraday sessions will allow lower SOC deviations. And therefore, smaller BESS will be required to operate the plant. This is due to the greater margin of operation (or higher frequency of chances) to modify energy commitments with the grid that this market configuration enables.

\section{ESS SIZING ANALYSIS}

The proposed PV + BESS operation control has been tested at three different locations of the Iberian Peninsula. These, corresponding to very different irradiance patterns, are placed in: the eastern part of Spain (in the Mediterranean coast at sea level, labelled as location A), the central plateau (800 $\mathrm{m}$ above sea level, labelled as $\mathrm{G}$ ), and the northern part of the country ( $420 \mathrm{~m}$ above sea level, labelled as $\mathrm{S})$. These present a total of 1560, 1510, and 1460 equivalent peak sun hours (PSH) per year on the horizontal plane, respectively. Thus, these locations with their different irradiance profiles cover quite a large casuistic of places susceptible to host a PV power plant. Moreover, thanks to data availability, various years have been analysed for each location what allows discounting some punctual climatic effects that could influence the analysis performed. In this sense, years 2016 to 2018 have been analysed for A and G while only 2016 and 2017 were available for S. For each of them, a set of simulations emulating the operation of the power plant every two minutes has been performed with seven different BESS sizes, ranging from $5 \mathrm{MWh}$ to $20 \mathrm{MWh}$.

The goal of the simulations, performed with Matlab ${ }^{\circledR}$, was to determine the amount of time per year that the system, with each of the defined BESS energy capacities, would be unable to track the committed power references ("Final ref" signal). In this sense, deviations with their corresponding cost can be evaluated together with the relationship between them and the costs that arise with the BESS introduction (and confronted to plant deviations without it).
Fig. 8 represents a 3D plot of the resulting annual SOC evolution for the operation of the plant with a $20 \mathrm{MWh}$ BESS at the location $G$ in 2016. It presents the day of the year in the " $x$ " axe, the number of sample in the " $y$ " axe, and SOC in the " $z$ " axe. Note how, with a large enough battery like the one considered, the SOC hardly arrives to completely charge or discharge. Therefore, it does not saturate it assures a perfect control of the PV+BESS plant. However, if the BESS was for instance half the size in terms of energy capacity, the saturation would be more frequent and would start to be of some importance.

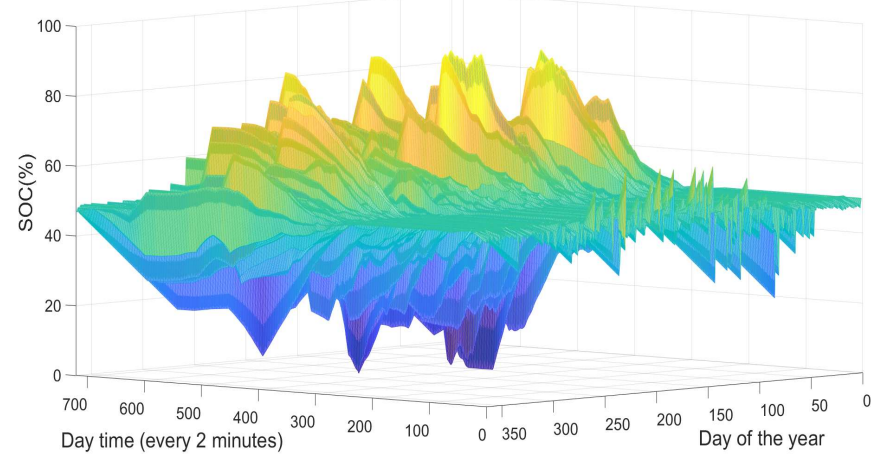

Fig. 8. Annual SOC evolution for a $20 \mathrm{MWh}$ BESS in G16.

This is just one case but, as described before, there are quite a lot of combinations of the parameters that have been simulated and analysed. These offer the results summarized in Table I and Table II. Both tables introduce for each of the different combinations of parameters considered what the percentage of time that the BESS would saturate is. These indicate in this way when the PV plant production would not be controlled and, therefore, commitment deviations would arise.

TABLE I. PERCENTAGE OF TIME IN A YEAR WHEN THE BESS SATURATES FOR A 6 SESSIONS INTRADAY MARKET CONFIGURATION.

\begin{tabular}{|c|c|c|c|c|c|c|c|c|}
\hline MWh & $\mathbf{A ~ 1 6}$ & $\mathbf{A ~ 1 7}$ & $\mathbf{A} \mathbf{1 8}$ & $\mathbf{G ~ 1 6}$ & $\mathbf{G ~ 1 7}$ & $\mathbf{G ~ 1 8}$ & $\mathbf{S} \mathbf{1 6}$ & $\mathbf{S ~ 1 7}$ \\
\hline $\mathbf{2 0}$ & 0.01 & 0.01 & 0.02 & 0.04 & 0.09 & 0.06 & 0.01 & 0.02 \\
\hline $\mathbf{1 7 . 5}$ & 0.04 & 0.03 & 0.04 & 0.12 & 0.17 & 0.14 & 0.04 & 0.05 \\
\hline $\mathbf{1 5}$ & 0.09 & 0.07 & 0.12 & 0.26 & 0.31 & 0.36 & 0.05 & 0.12 \\
\hline $\mathbf{1 2 . 5}$ & 0.28 & 0.23 & 0.34 & 0.68 & 0.61 & 0.83 & 0.21 & 0.24 \\
\hline $\mathbf{1 0}$ & 0.91 & 0.73 & 0.84 & 1.51 & 1.28 & 1.90 & 0.72 & 0.64 \\
\hline $\mathbf{7 . 5}$ & 2.46 & 1.90 & 2.14 & 3.47 & 2.96 & 3.98 & 2.31 & 1.87 \\
\hline $\mathbf{5}$ & 6.06 & 5.23 & 5.12 & 7.32 & 6.98 & 7.93 & 6.24 & 5.86 \\
\hline
\end{tabular}

TABLE II. PERCENTAGE OF TIME IN A YEAR WHEN THE BESS SATURATES FOR A 8 SESSIONS INTRADAY MARKET CONFIGURATION.

\begin{tabular}{|c|c|c|c|c|c|c|c|c|}
\hline MWh & A 16 & A 17 & A 18 & G 16 & G 17 & G 18 & S 16 & S 17 \\
\hline $\mathbf{2 0}$ & 0.00 & 0.00 & 0.01 & 0.01 & 0.02 & 0.05 & 0.01 & 0.00 \\
\hline $\mathbf{1 7 . 5}$ & 0.00 & 0.01 & 0.01 & 0.07 & 0.06 & 0.06 & 0.02 & 0.00 \\
\hline $\mathbf{1 5}$ & 0.02 & 0.03 & 0.03 & 0.16 & 0.16 & 0.08 & 0.02 & 0.04 \\
\hline $\mathbf{1 2 . 5}$ & 0.08 & 0.08 & 0.13 & 0.30 & 0.31 & 0.21 & 0.10 & 0.12 \\
\hline $\mathbf{1 0}$ & 0.25 & 0.18 & 0.33 & 0.64 & 0.59 & 0.61 & 0.43 & 0.32 \\
\hline $\mathbf{7 . 5}$ & 0.88 & 0.67 & 0.95 & 1.55 & 1.28 & 1.67 & 1.44 & 1.09 \\
\hline $\mathbf{5}$ & 2.81 & 2.44 & 2.60 & 3.67 & 3.33 & 4.37 & 4.20 & 3.76 \\
\hline
\end{tabular}

For the sake of clarity, the numerical values from these tables are represented in Fig. 9. Note how the BESS gets 
much more saturated for the 6-session intraday configuration (curves on the left-hand side of the graph). If the smallest BESS case is analysed for comparison, while saturation is, according to the tables, around $2.6 \%, 3.8 \%$ and $4 \%$ of the time in average for the three locations, respectively, and for the 8 -session market, it gets up to $5.5 \%, 7.4 \%$ and $6 \%$ of the time in average respectively for the 6-session market. Therefore, it can be concluded that thanks to the improved intraday market configuration with 8 sessions proposed by OMIE, the BESS energy capacity requirements for solar PV merchant plants capacity firming could be reduced in the range of $25 \%$ to $50 \%$ in terms of energy capacity depending on the location. This would imply an important reduction in the CAPEX of the plant that would make it easier for this type of technology to skyrocket.

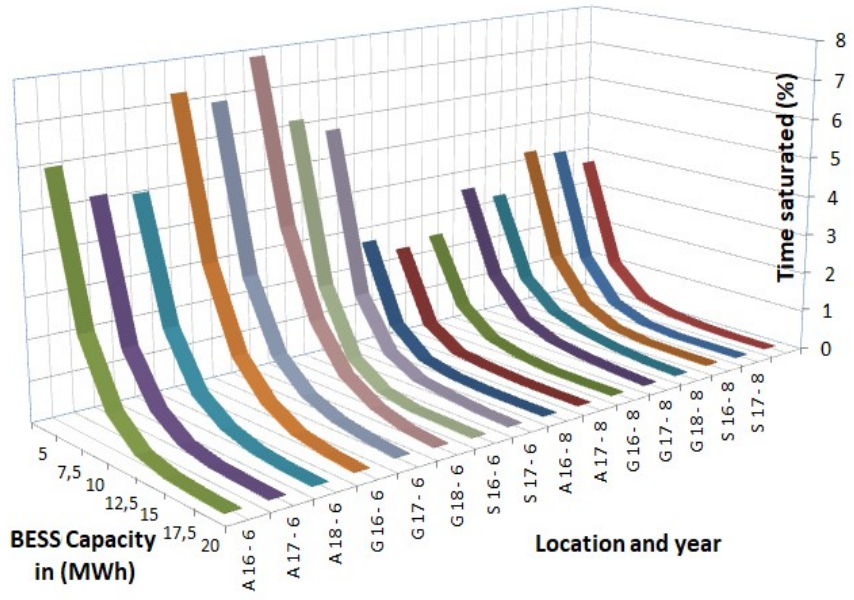

Fig. 9. Graphical representation of the results registered in Tables I \& II.

However, it also should be concluded that even with the 6-session intraday market structure currently driving the MIBEL market, thanks to the use of the clustering algorithm with the past PV production (or measured irradiance) the amount of energy capacity required to BESS to provide a good PV capacity firming could be acceptable since it is significantly lower than that being implemented nowadays as a substitute of thermal peaker plants [8].

\section{CONCLUSIONS}

This paper has analysed the minimum energy capacity requirements to be demanded to BESS used in a $10 \mathrm{MW}$ rated-power merchant solar PV plant in order to grant it with capacity firming. The analysis has been carried on an annual basis, using real irradiance data measured every two minutes at three different locations of the Iberian Peninsula, a clusterbased irradiance forecast, and two different electricity market intraday configurations. The operation of the plant has been optimized for each of the combinations, battery sizes and locations by solving a quadratic programming problem which intended to minimize the PV+BESS production deviation (with regard to that traded in the market). Results confirm that the 8-session intraday market structure would benefit this kind of installations in terms of CAPEX since the shorter time in between auction and operation period would allow using smaller batteries. Moreover, it can be concluded that thanks to the irradiance clustering strategy, batteries with energy capacities below two hours would provide capacity firming to merchant PV solar plants minimizing deviations to very low rates (below $1 \%$ of the time annually).

\section{ACKNOWLEDGMENT}

The authors would like to thank the Universitat Jaume I (Spain) and the Generalitat Valenciana for their financial support via the projects with codes UJI-B2017-26, PREDOC-2018-13 and GV-2019-087.

\section{REFERENCES}

[1] A. Whiteman, J. Esparrago, S. Rueda, S. Elsayed, and I. Arkhipova, IRENA (2019), Renewable capacity statistics 2019. Abu Dhabi.

[2] C. S. Lai and M. D. McCulloch, 'Levelized cost of electricity for solar photovoltaic and electrical energy storage', Appl. Energy, vol. 190, pp. 191-203, 2017.

[3] F. Katiraei and J. Romero Aguero, 'Solar PV Integration Challenges', IEEE Power Energy Mag., vol. 9, no. 3, pp. 62-71, 2011.

[4] O. Schmidt, S. Melchior, A. Hawkes, and I. Staffell, 'Projecting the Future Levelized Cost of Electricity Storage Technologies', Joule, vol. 3, no. 1, pp. 81-100, Jan. 2019.

[5] X. Li, D. Hui, and X. Lai, 'Battery energy storage station (BESS)based smoothing control of photovoltaic (PV) and wind power generation fluctuations', IEEE Trans. Sustain. Energy, vol. 4, no. 2, pp. 464-473, 2013.

[6] H. Beltran, I. Tomas Garcia, J. C. Alfonso-Gil, and E. Perez, 'Levelized Cost of Storage for Li-Ion Batteries Used in PV Power Plants for Ramp-Rate Control', IEEE Trans. Energy Convers., vol. 34, no. 1, pp. 554-561, 2019.

[7] M. N. Kabir, Y. Mishra, G. Ledwich, Z. Y. Dong, and K. P. Wong, 'Coordinated control of grid-connected photovoltaic reactive power and battery energy storage systems to improve the voltage profile of a residential distribution feeder', IEEE Trans. Ind. Informatics, vol. 10, no. 2, pp. 967-977, 2014.

[8] D. C. Wagman, 'Energy Storage Projects to Replace Three Natural Gas Power Plants in California', IEEE Spectrum, 2018. [Online]. Available:

https://spectrum.ieee.org/energywise/energy/renewables/energystorage-projects-to-replace-three-natural-gas-power-plants-incalifornia.

[9] F. Borggrefe and K. Neuhoff, 'Balancing and Intraday Market Design: Options for Wind Integration', 2011

[10] K. Rademaekers, A. Slingenberg, and S. Morsy, 'Review and analysis of EU wholesale energy markets', Rotterdam, 2008.

[11] OMIE, 'Intraday market', 2018. [Online]. Available: http://m.omie.es/en/home/markets-and-products/electricitymarket/our-electricity-markets/intraday-market?m=yes. [Accessed: 15-Apr-2019]

[12] H. Beltran, E. Perez, N. Aparicio, and P. Rodriguez, 'Daily Solar Energy Estimation for Minimizing Energy Storage Requirements in PV Power Plants', IEEE Trans. Sustain. Energy, vol. 4, no. 2, pp. 474-481, 2013

[13] Y. Riffonneau, S. Bacha, F. Barruel, and S. Ploix, 'Optimal power flow management for grid connected PV systems with batteries', Sustain. Energy, IEEE Trans., vol. 2, no. 3, pp. 1-320, 2011.

[14] M. Lafoz, L. Garcia-Tabares, and M. Blanco, 'Energy Management in solar photovoltaic plants based on ESS', in Power Electronics and Motion Control Conference, 2008. EPE-PEMC 2008. 13th, 2008, pp. 2481-2486.

[15] H. Kanchev, D. Lu, F. Colas, V. Lazarov, and B. Francois, 'Energy Management and Operational Planning of a Microgrid With a PVBased Active Generator for Smart Grid Applications', Ind. Electron. IEEE Trans., vol. 58, no. 10, pp. 4583-4592, 2011.

[16] H. Fakham, D. Lu, and B. Francois, 'Power Control Design of a Battery Charger in a Hybrid Active PV Generator for Load-Following Applications', Ind. Electron. IEEE Trans., vol. 58, no. 1, pp. 85-94, 2011.

[17] H. Beltran, E. Bilbao, E. Belenguer, I. Etxeberria-Otadui, and P. Rodriguez, 'Evaluation of Storage Energy Requirements for Constant Production in PV Power Plants', Ind. Electron. IEEE Trans., vol. 60, no. 3, pp. 1225-1234, 2013.

[18] D. A. and S. Vassilvitskii, 'k-means++: The Advantages of Careful Seeding', in Proceedings of the eighteenth annual ACM-SIAM symposium on Discrete algorithms, Society for Industrial and Applied Mathematics., 2007. 